\title{
Effect of Reclamation on the Skin Layer of Ductile Iron Cast in Furan Molds
}

\author{
R. Dańko, M. Holtzer, M. Górny, and S. Żymankowska-Kumon
}

(Submitted May 27, 2013; in revised form July 2, 2013; published online July 23, 2013)

\begin{abstract}
The paper presents the results of investigations of the influence of the quality of molding sand with furan resin hardened by paratoluenesulfonic acid, on the formation of microstructure and surface quality of ductile iron castings. Within the studies different molding sands were used: molding sand prepared with fresh sand and molding sands prepared with reclaimed sands of a different purification degree, determined by the ignition loss value. Various concentrations of sulfur and nitrogen in the sand molds as a function of the ignition loss were shown in the paper. A series of experimental melts of ductile iron in molds made of molding sand characterized by different levels of surface-active elements (e.g., sulfur) and different gas evolution rates were performed. It was shown that there exists a significant effect of the quality of the sand on the formation of the graphite degeneration layer.
\end{abstract}

Keywords casting skin, ductile iron, graphite degeneration, molding sand

\section{Introduction}

Production of castings (especially thin-walled) of ductile iron, in loose self-hardening molding sands with furfuryl resin hardened by paratoluenesulfonic acid, brings a danger of forming defected casting microstructure, which the most often occurs in its surface layer (Ref 1-10). This unfavorable effect is caused by sulfur contained in a hardener of resin binders, which enters the surface layer causing degradation of a nodular graphite into flake graphite. In such case the degenerated surface layer can cause stress raising in the casting, similar to a notch, so all useful properties are reduced, especially the fatigue limit and impact resistance. The graphite degradation in the surface layer is the most critical for thin wall castings, where it could become more than $10 \%$ of the total section. It affects also castings of thicker walls, due to the long solidification time providing an extended metal/mold interaction time.

The authors of the hereby paper undertook the effort of making test castings of ductile iron in molds made of a fresh molding sand and of a molding sand with a reclaim of various purification degrees. Then the castings were subjected to investigations leading to determination of the microstructure of their skin layer directly adhering to the mold. Simultaneously, the gas evolution and sulfur and nitrogen contents were determined for molding sands, of which molds were made.

R. Dańko, M. Holtzer, M. Górny, and S. Żymankowska-Kumon, AGH-University of Science and Technology, Reymonta 23, 30-059 Cracow, Poland. Contact e-mail: mgorny@agh.edu.pl.

\section{Experimental Tests}

Experimental castings applied in investigations were test bars, according to the ASTM A 536-84 standard, of a wall thickness in the working part: $13 \mathrm{~mm}$. Four casting molds were made of molding sands marked with symbols: MT1-1-MT1-4. All tested molding sands were prepared with furan-urea Kaltharz U404 resin and 100T3 hardener. The following molding sand composition was applied:

- Matrix (high-silica sand or reclaim) - 98.5 wt.\%,

- Furfuryl resin-1.0 wt.\% of the sand batch,

- Hardener (paratoluenesulfonic acid) -0.5 wt. $\%$ of the sand batch.

Molding sands matrices were as follows:

- High-silica sand-molding sand MT1-1,

- Reclaim 1 (after one cycle of a reclamation treatment) -MT1-2,

- Reclaim 2 (after two cycles of a reclamation treatment) -MT1-3,

- Reclaim 3 (after three cycles of a reclamation treatment) -MT1-4.

Reclaims were obtained in the experimental mechanical, rotor reclaimer. Grain size analyses and grain characteristic values of materials used for matrices are presented in Table 1. Grain size analysis was performed by means of the laser apparatus Analysette 22 NanoTec for measuring particle sizes.

It can be noticed that the ignition loss of molding sand after three cycles of a reclamation treatment is 2.9 times larger than of molding sand prepared on the fresh high-silica sand. The matrix also has increased ignition losses when the number of cycles is increasing, which indicates that a spent binder, not removed during the reclamation treatment preceding the molding sand preparation, is cumulating on matrix grains (Ref 11). The observed effect constituted the reason for investigating of sulfur and nitrogen content in molding sands and their gas evolution rates. 
Table 1 Grain size analysis and ignition loss of molding sands and matrices applied for preparing test molding sands: MT1-1 through MT1-4

Characteristic of matrix subjected to different number of cycles

\begin{tabular}{|c|c|c|c|c|c|c|}
\hline \multirow[b]{2}{*}{ Molding sand notation } & \multicolumn{2}{|c|}{ Characteristic of molding sands } & \multicolumn{3}{|c|}{$\begin{array}{l}\text { Grain size analysis (Analisette } 22 \\
\text { NanoTec) }\end{array}$} & \multirow{2}{*}{$\begin{array}{l}\text { Ignition loss } \\
\mathrm{SP}_{(\mathrm{P})} \mathrm{SP}_{(\mathrm{R})}, \%\end{array}$} \\
\hline & Kind of matrix & Ignition loss $\mathrm{SP}_{(\mathrm{mz})}, \%$ & $d_{\mathrm{a}}, \mathbf{m m}$ & $d_{\mathrm{g}}, \mathbf{m m}$ & $S_{\mathrm{t}}, \mathrm{cm}^{2} / \mathrm{g}$ & \\
\hline Molding sand MT1-1 & High-silica sand & 1.47 & 0.287 & 0.235 & 1173 & 0.02 \\
\hline Molding sand MT1-2 & Reclaim after 1 cycle & 2.89 & 0.304 & 0.241 & 1713 & 1.44 \\
\hline Molding sand MT1-3 & Reclaim after 2 cycles & 3.86 & 0.305 & 0.243 & 1777 & 2.41 \\
\hline Molding sand MT1-4 & Reclaim after 3 cycles & 4.26 & 0.312 & 0.252 & 1812 & 2.81 \\
\hline
\end{tabular}

$d_{\mathrm{a}}$, average arithmetic grain diameter $(\mathrm{mm}) ; d_{\mathrm{g}}$, average geometric grain diameter $(\mathrm{mm}) ; S_{\mathrm{t}}$, specific surface $\left(\mathrm{cm}^{2} / \mathrm{g}\right) ; \mathrm{SP}_{(\mathrm{mz})}$, ignition loss of molding sand $(\%) ; \mathrm{SP}_{(\mathrm{R})}$, ignition loss of reclaim used for preparing molding sand $(\%)$; $\mathrm{SP}_{(\mathrm{P})}$, ignition loss of fresh silica sand used for preparing molding sand $(\%)$
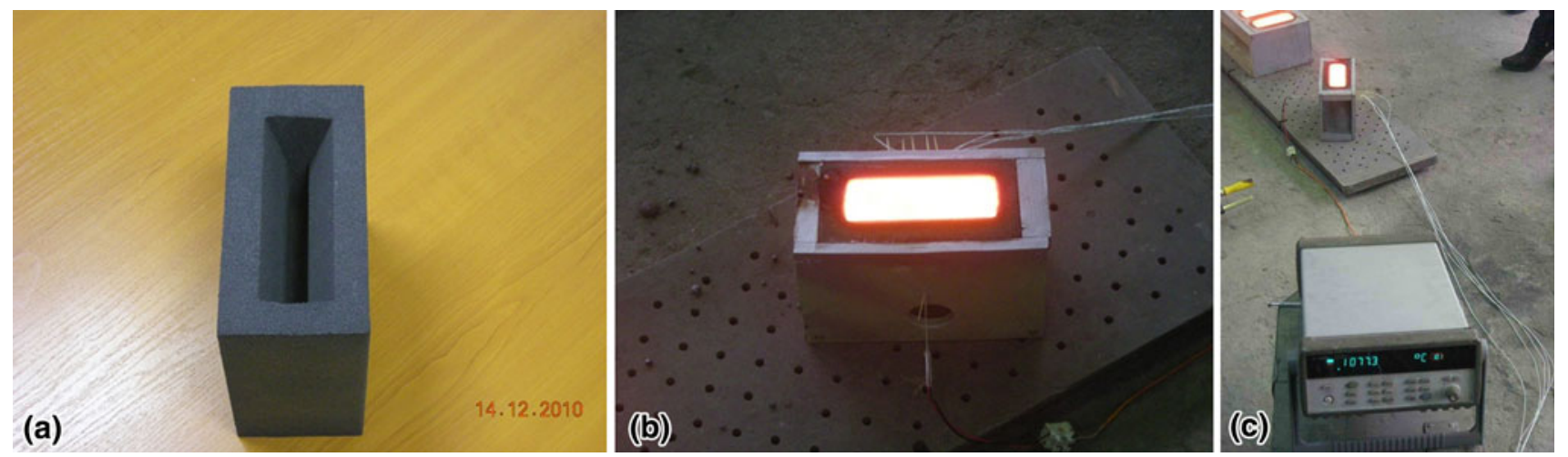

Fig. 1 View of the foundry mold before pouring (a) and after pouring (b), set up for temperature measuring (c)

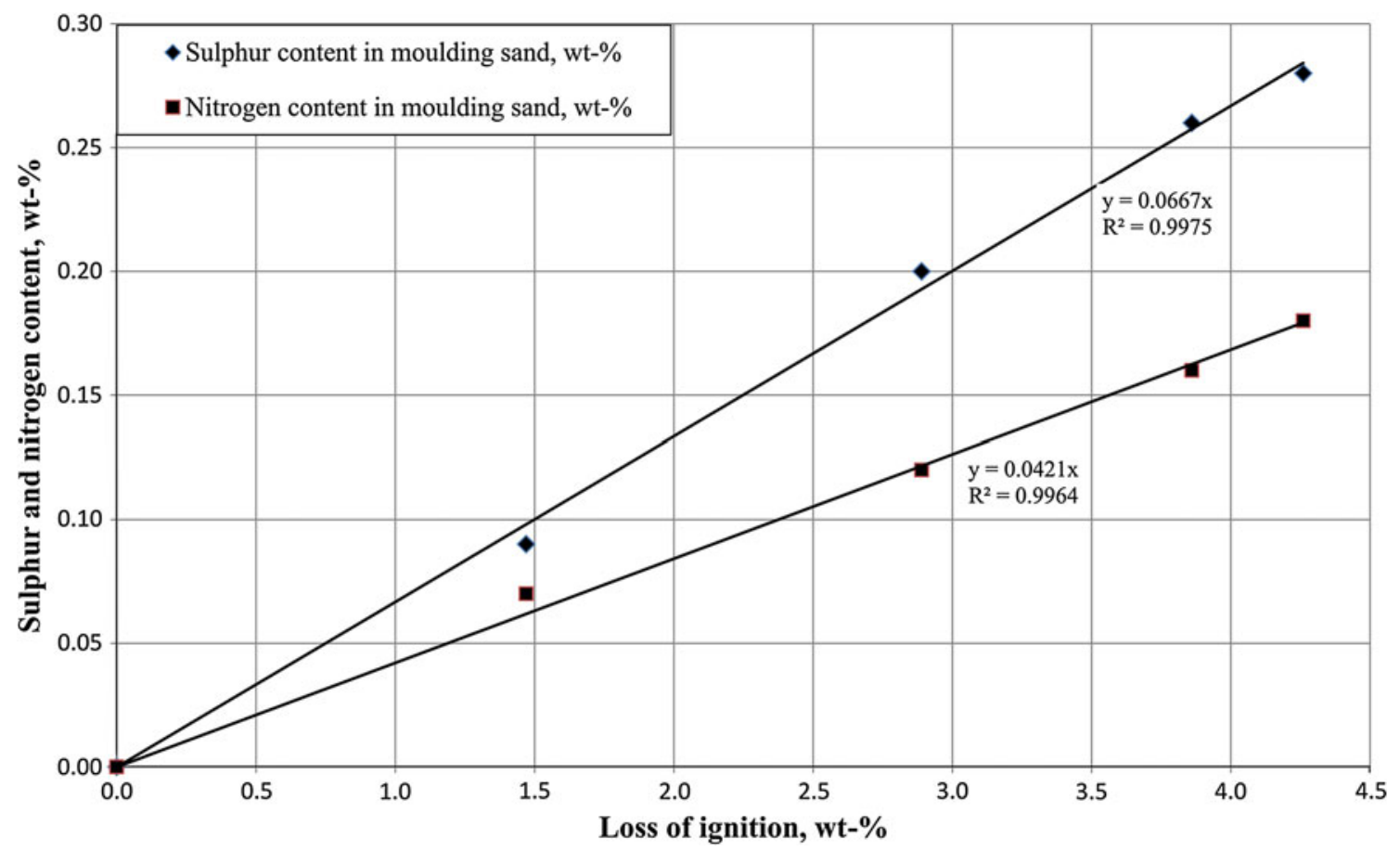

Fig. 2 Sulfur $(\mathrm{S})$ and nitrogen $(\mathrm{N})$ content in molding sands with furan resin (1 mass \%) and hardener $(0.5$ mass $\%)$. Ignition losses as in Table 1 


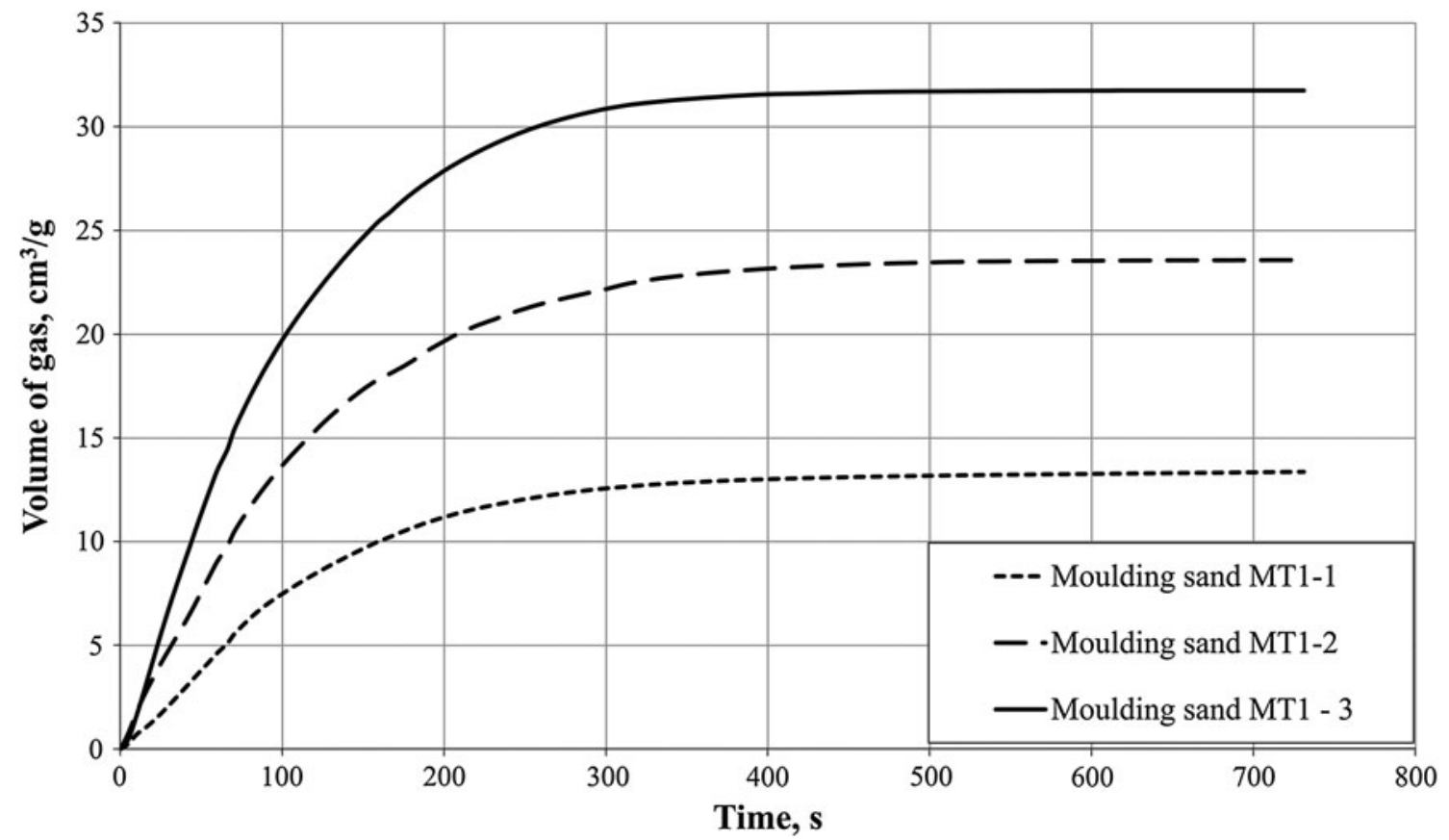

Fig. 3 Volume of gases emitted by the investigated molding sands in the process of their pouring with liquid metal. Pouring temperature: $1400{ }^{\circ} \mathrm{C}$

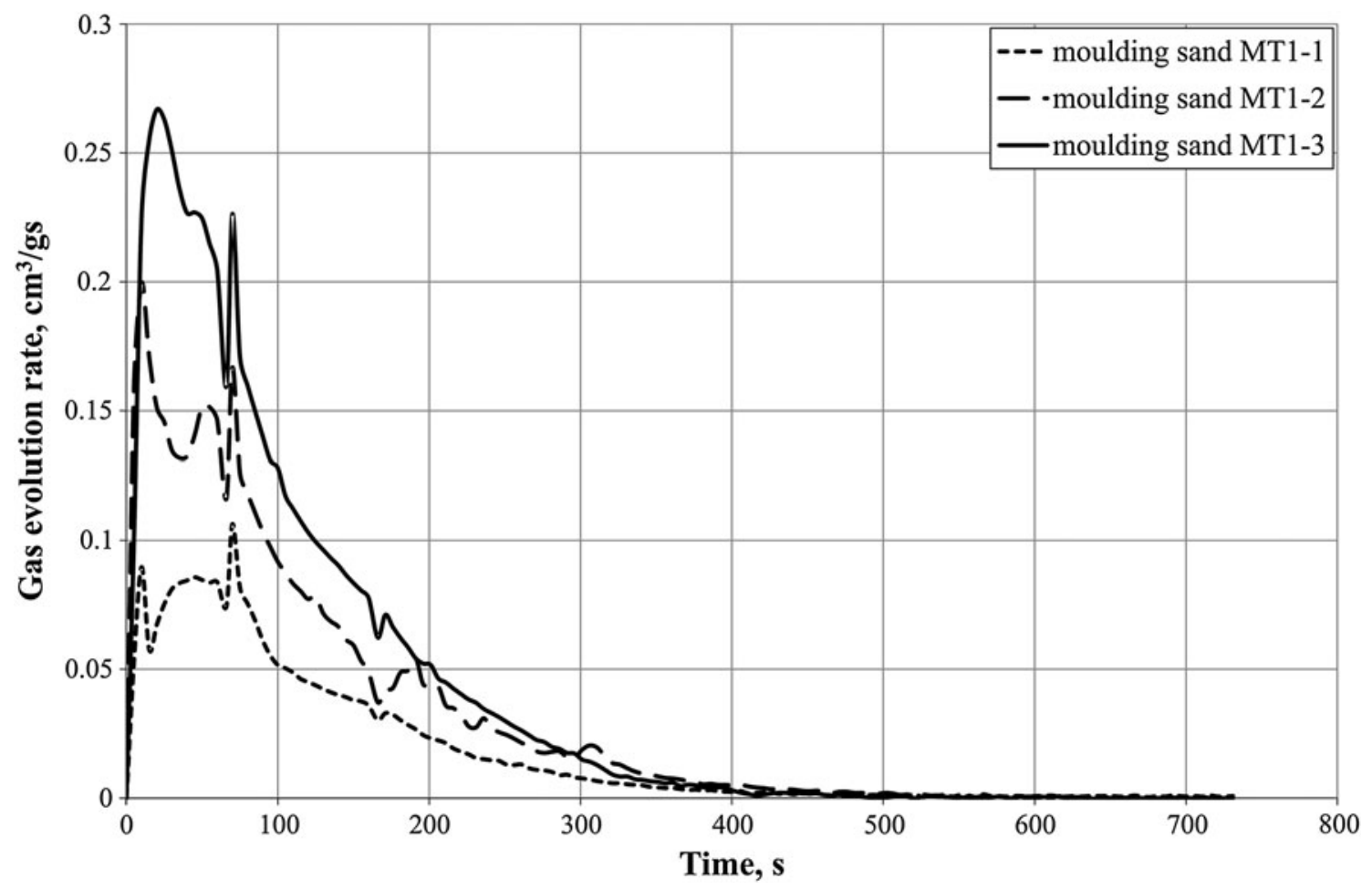

Fig. 4 Kinetics of gases emitted by the investigated molding sands in the process of their pouring with liquid metal. Pouring temperature: $1400{ }^{\circ} \mathrm{C}$

The experimental melt was performed in an induction furnace. The furnace charge consisted of the following materials: Sorelmetal, silicon of technical purity, Fe-Mn, and steel scrap. After heating the metal to a temperature of $1490{ }^{\circ} \mathrm{C}$ the bath was hold for 2 min and then spheroidizing and inoculation by the bell method was carried out. For the spheroidization treatment the foundry alloy $\mathrm{Fe}-\mathrm{Si}-\mathrm{Mg}$ ( $\mathrm{Si} 44-$ 48 wt.\%, Mg 5.5-6.2 wt.\%, RE 0.8-1.2 wt.\%, Ca 0.8-1.2 wt.\%, 


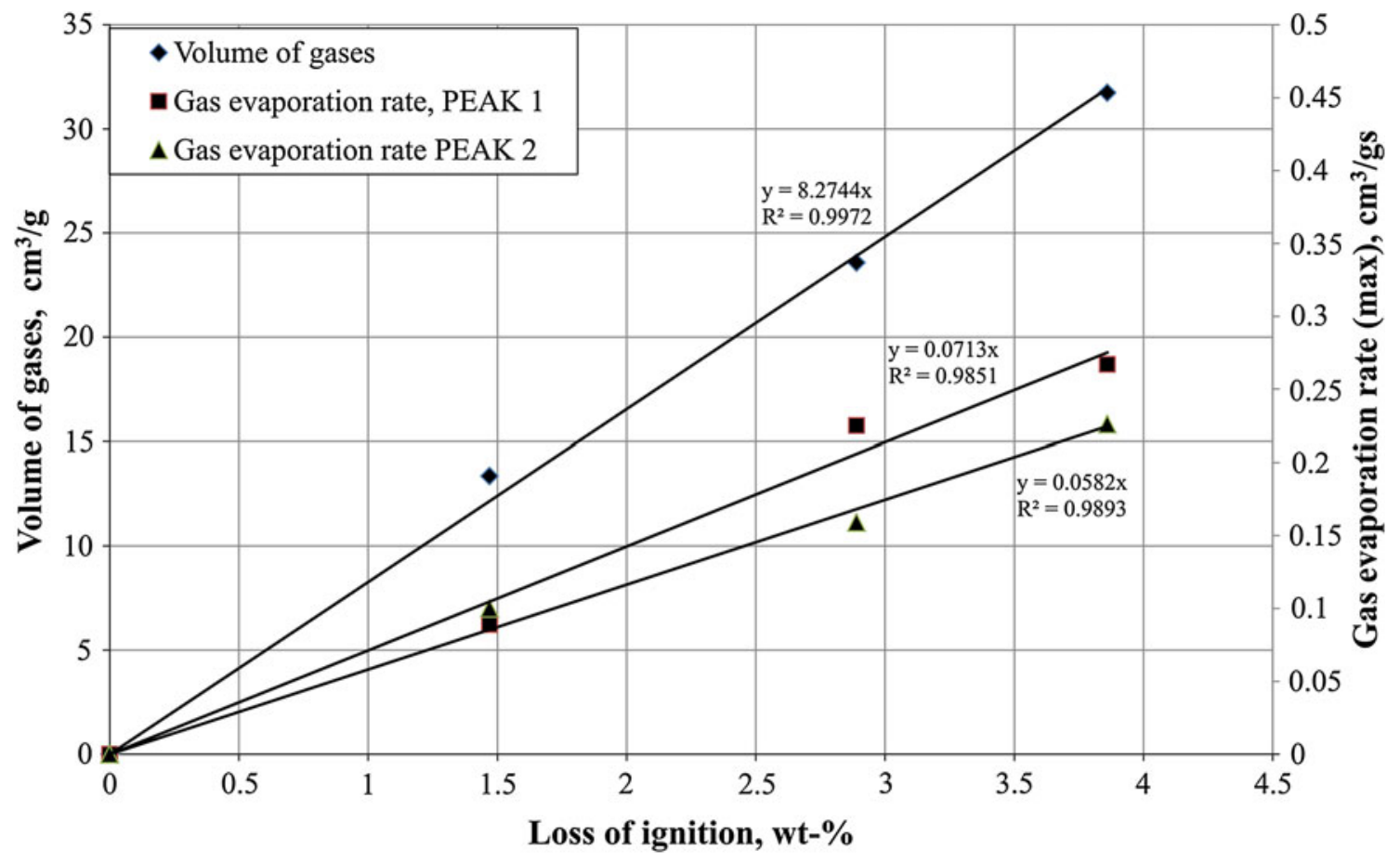

Fig. 5 Volume and kinetics of gases generated as the result of pouring test bars — made of the investigated molding sands—as a function of ignition losses of these sands

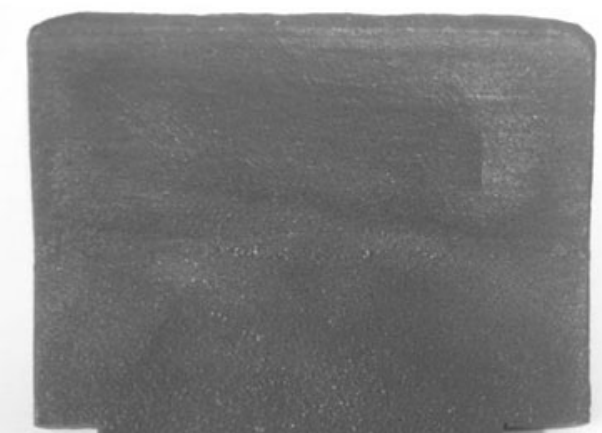

(a)

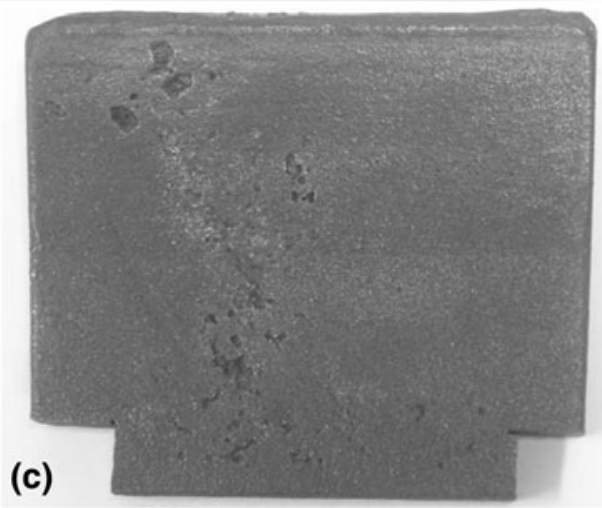

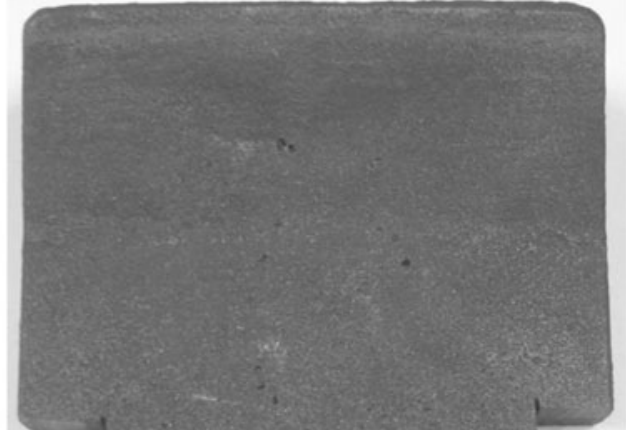

(b)

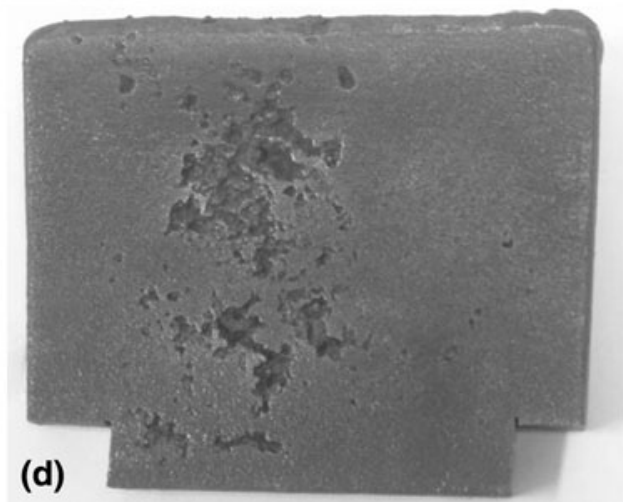

Fig. 6 Experimental castings: (a) casting made in the mold of molding sand 1, (b) casting made in the mold of molding sand 2, (c) casting made in the mold of molding sand 3, (d) casting made in the mold of molding sand 4

Al $1.0 \mathrm{wt} \%$, Fe rest) was used, while for the inoculation an inoculant (Ca 0.75-1.25 wt.\%, Ba 0.75-1.25 wt.\%, Al 0.751.25 wt. $\%$, Si $73-78$ wt.\%, Fe rest) was used in amount of
0.5 wt. $\%$. The pouring temperature was approximately $1400{ }^{\circ} \mathrm{C}$. Four Y block ingots according to ASTM A 536-84 were prepared from self-hardening molding sands (MT1-1 


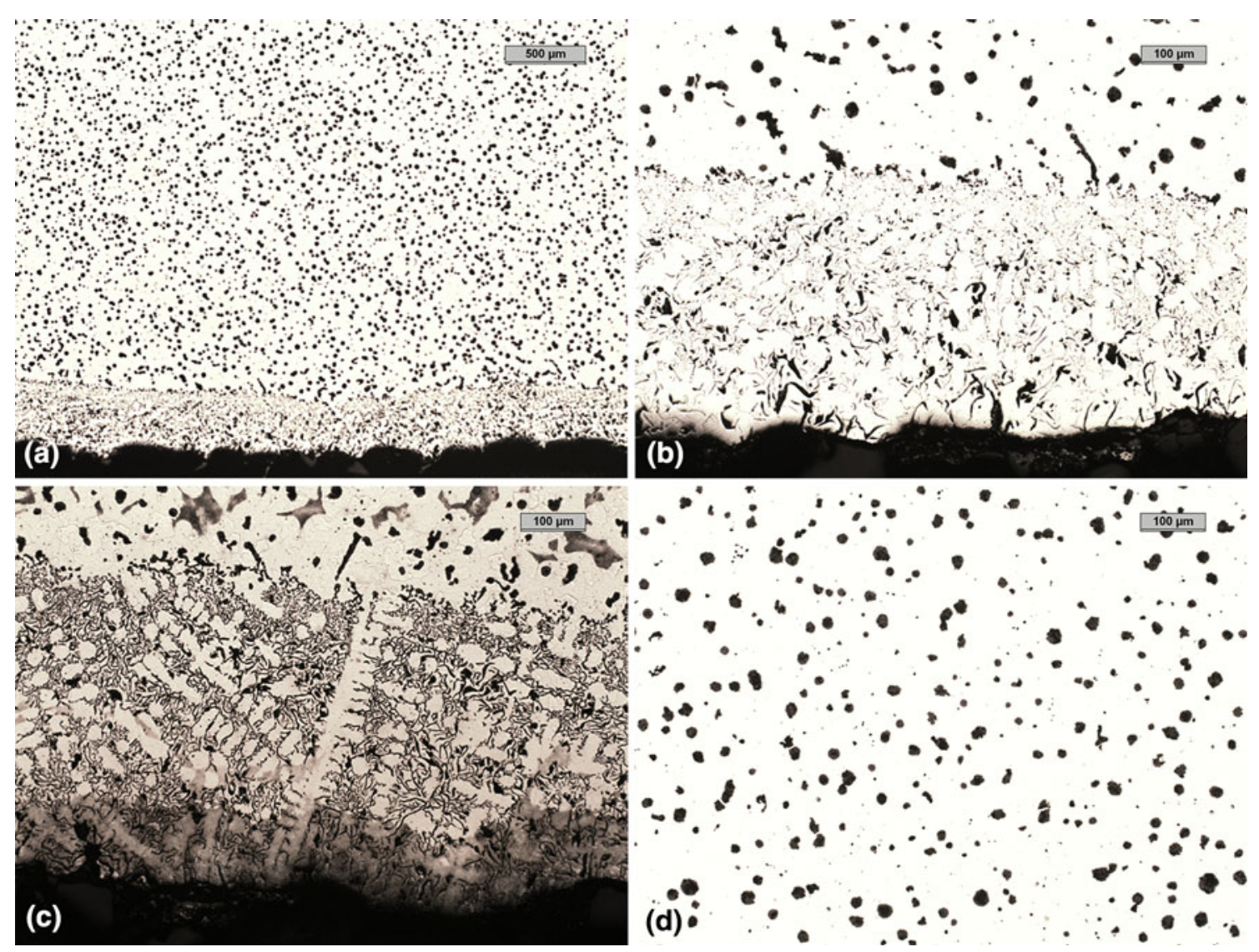

Fig. 7 Photographs of the microstructure of the casting made in the mold of molding sand 1: (a) magnification $25 \times$-view from the molding sand side, (b) magnification $100 \times$ - view from the molding sand side, (c) magnification $100 \times$ (polished section etched with nital), (d) magnification $100 \times$, middle of the casting

through MT1-4) of a characteristic given in Table 1. Diversification of ignition losses of molding sands was a result of different number of cycles, in which participated the given molding sand matrix.

The thermal load of a molding sand during test castings, expressed by a ratio of casting mass to molding sand mass was: $m_{\text {cast }}: m_{\text {mold }}=1: 1.6$ (at the casting mass equal $1.7 \mathrm{~kg}$ ). The average apparent density of the compacted molding sand was approximately $1600 \mathrm{~kg} / \mathrm{m}^{3}$. After the mold pouring with ductile iron the temperature was measured in the mold during casting cooling. Ductile iron of the following chemical composition was obtained: C 3.56\%; Si 2.99\%; Mn 0.29 wt.\%; P 0.046 wt.\%; S 0.011 wt.\%; Cr 0.03 wt.\%; Mg 0.046 wt.\%; Cu 0.02 wt.\%. The performed strength investigations allowed to determine the grade of the melted ductile iron as ASTM A536 65-45-12.

The view of molds on the experimental stand for testing the thermal degradation of the molding sand with the furan resin is presented in Fig. 1.

Samples cut out from lower parts of test ingots were subjected to metallographic and strength investigations. From geometrical center of the bottom part of each ingot metallographic investigations were carried out by means of the optical microscope Leica MEF-4M. The microstructure was assessed at magnifications 25 and $100 \times$. The ductile iron classification, on the basis of the static tensile test was performed by means of the Zwick/Roell Z050 device equipped with the extensometer Macro. The testing rate was $0.008 \mathrm{~s}^{-1}$.

\section{Investigation Results}

\subsection{Determination of Sulfur and Nitrogen Content in Molding Sands}

The literature data (Ref 4, 8, 9) emphasize a disadvantageous influence of too high sulfur and nitrogen content in molding sands on the microstructure of the obtained castings surfaces.

Within quality investigations of the reclaimed matrix the sulfur and nitrogen content in four molding sands (listed in Table 1) were performed in the Carbochemistry Laboratory of the Institute of the Chemical Carbon Treatment in Zabrze.

The obtained results presented graphically in Fig. 2 confirm the accumulation effect of sulfur and nitrogen in molding sands after several reclamation treatments. The increase of sulfur and nitrogen content in molding sands as a function of ignition losses exhibits nearly linear character. Thus, it seems possible to determine indirectly these elements content in molding sands on the basis of knowledge of 


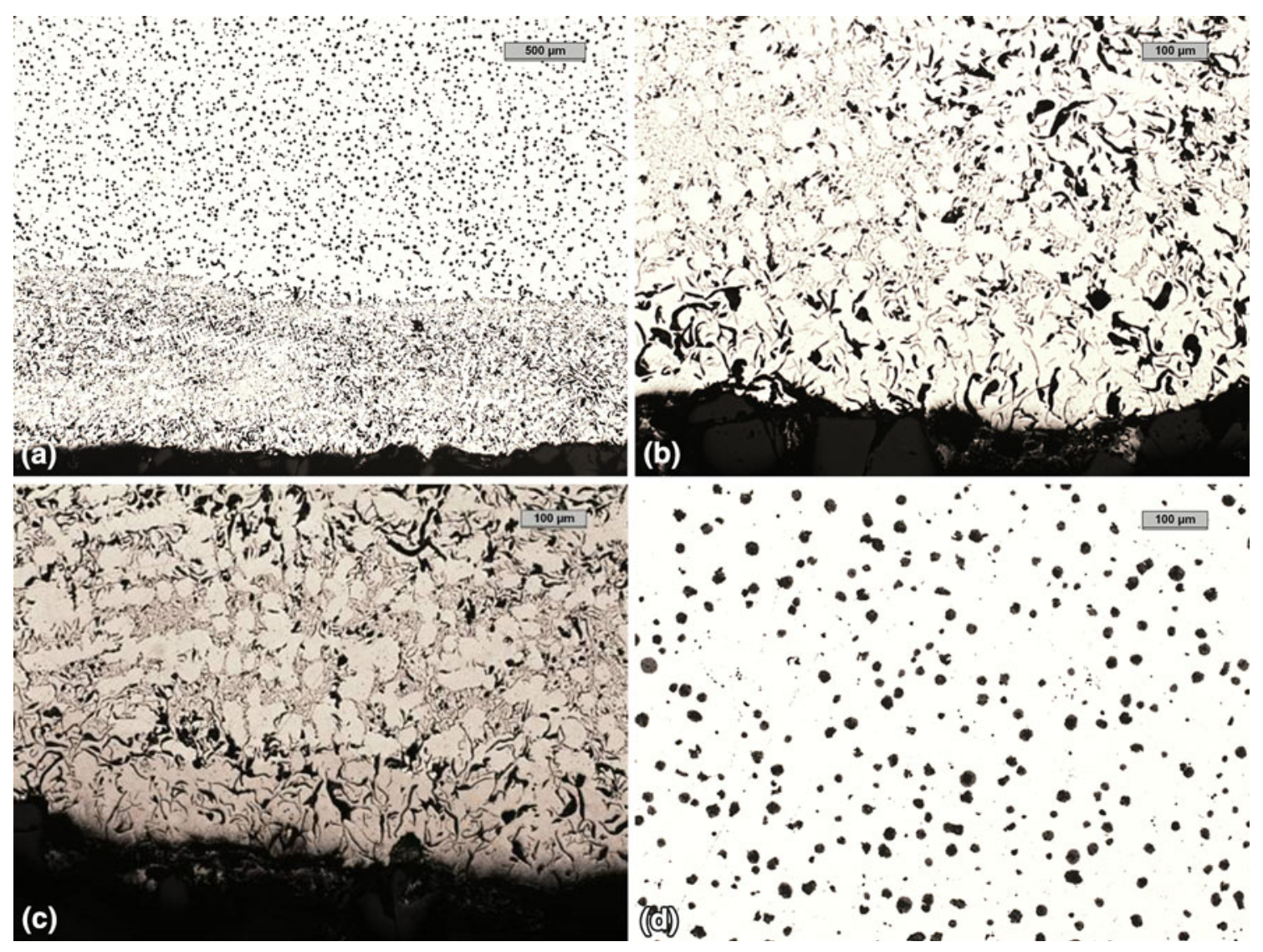

Fig. 8 Photographs of the microstructure of the casting made in the mold of molding sand 2: (a) magnification $25 \times$ - view from the molding sand side, (b) magnification $100 \times$ - view from the molding sand side, (c) magnification $100 \times$ (polished section etched with nital), (d) magnification $100 \times$, middle of the casting

ignition losses and its characteristic similar to the one presented in Fig. 2.

\subsection{Gas Volumetric Emission from Molding Sands}

During a casting production process an intensive thermal destruction of organic components of molding sands occurs, causing a large emission of gases. These gases constitute a threat for the casting quality, since they can migrate into a casting and worsen its surface.

Own investigations of gases emission were carried out according to the original method developed in the Faculty of Foundry Engineering AGH (Ref 12).

Investigations of the amounts and kinetics of gases generated in the process of pouring test bars were performed for the given above variants of molding sands (MT1-1 through MT1-3), which characteristic is presented in Table 1. The obtained gases emissivity pathways are presented in Fig. 3 as a time function. It can be noticed that the amount of gases generated from molding sand with furfuryl resin depends on the ignition loss of this sand. With an increase of ignition losses an amount of gases generated in the mold pouring process also increases.
The highest intensity of gases emission takes place directly after the mold pouring with liquid metal. The kinetics of gases emission, presented in Fig. 4, allows to state that - under tests conditions - the highest gas evolution rate peaks is in the first $90 \mathrm{~s}$ after pouring.

The analysis of pathways indicates that both the volume and kinetics of emitted gases depends essentially on the ignition losses of molding sands. Volumes of gases generated by molding sands as the function of ignition losses of these sands are presented in Fig. 5. It can be seen that using the molding sand of a higher ignition loss causes a directly proportional increase of gases emission. A similar inference results from the analysis of maximum values on the curve of the kinetics of gases emission presented in the same figure.

On the basis of macroscopic photographs (Fig. 6) of casting surfaces differences in their qualities in dependence on the material from which the mold was made, can be seen. It should be emphasized that all castings were performed under the same conditions, it means that from one melt four castings were made. The casting made in the mold from the molding sand 1 has the best, visually assessed, surface quality. Certain small defects are seen on the casting made in the mold of molding sand 2 and these defects become more visible on the castings made in the mold of molding sand 3 and 4 . Investigations of 

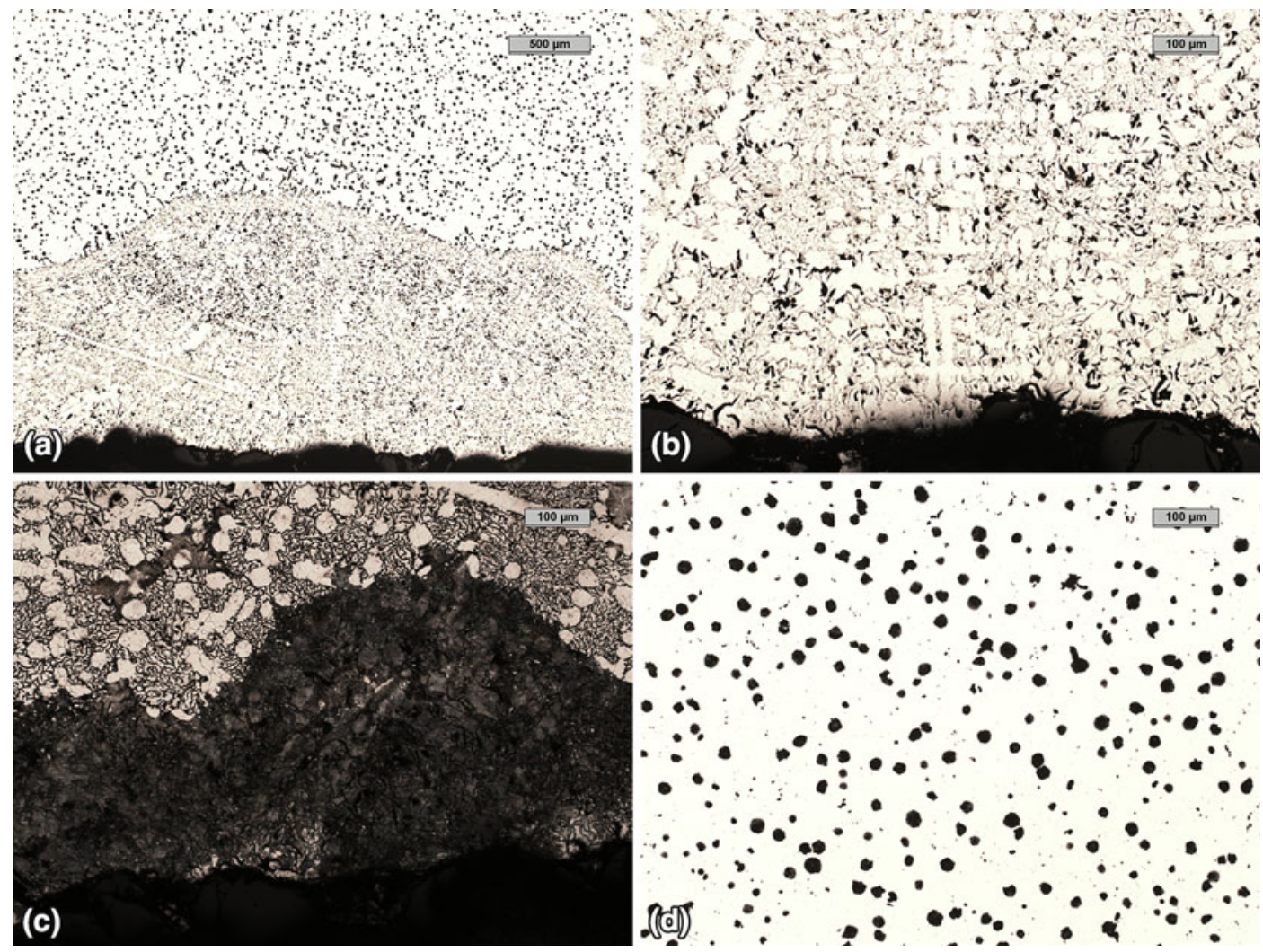

Fig. 9 Photographs of the microstructure of the casting made in the mold of molding sand 3: (a) magnification $25 \times$-view from the molding sand side, (b) magnification $100 \times$ - view from the molding sand side, (c) magnification $100 \times$ (polished section etched with nital), (d) magnification $100 \times$, middle of the casting

gas evolution rate of molding sands 1-3 confirmed that the amount of gases, which source is the foundry mold material is, in practice, linearly dependent on ignition losses of molding sands. The obtained castings confirm this fact, since casting defects formed in them are defects being the result of a high evolution rate of gases.

\subsection{Investigations of Casting Microstructures}

The metallographic examination shows that microstructure of ductile iron in bottom part of the examinated ingots is composed of spheroidal graphite (type I) and ferritic-pearlitic (approximately $15 \%$ of pearlite) matrix. Microstructures at the interface of metal-mold of ductile iron obtained for the investigated molding sands are presented in Fig. 7, 8, 9, and 10 in such a way that the dark zone on the bottom means the metal and molding sand contact.

The presented above results of investigations of microstructures of castings indicate that with the increase of ignition losses of molding sands, of which the mold was made (molding sand 1-molding sand 4) the thickness of the flake graphite layer-located at the metal-mold contact-increases. The mold production with using reclaimed materials of higher ignition losses (it means of larger amounts of spent binder left on matrix grains) causes that the thickness of flake graphite layer increases. On the basis of casting microstructures investigations the average thickness of degenerated nodular graphite and pearlite layers - which are forming from the molding sand side - were estimated. The results are presented in Fig. 11. It can be noticed that the thickness of these layers is increasing when the ignition loss of molding sand out of which the mold was produced is increasing. In case of the casting produced of fresh molding sands (for which sulfur and nitrogen content was determined as being 0.09 and 0.07 wt. $\%$, respectively, and ignition loss $=1.46 \mathrm{wt} . \%$ ) the thickness of these layers is the smallest. However, also in this case there is a zone in which the nodular graphite, muchdesired from the casting point of view, was degenerated. In case of the casting four microstructure (Fig. 10), for which the mold was produced of the molding sand containing $0.24 \mathrm{wt} . \%$ of sulfur and $0.14 \mathrm{wt} . \%$ of nitrogen (ignition loss $=4.26 \mathrm{wt} . \%$ ) the maximum thickness of the degenerated graphite layer was nearly $1.5 \mathrm{~mm}$.

Increasing thickness of graphite and pearlite layers are due to interactions of sulfur with metal at the boundary metal-mold. The graphite degeneration is caused by decreasing the magnesium concentration (spheroidizing element) in the ductile iron near-surface layer since magnesium reacts with sulfur or oxygen, which diffuses from molding sand to metal. Thus, the higher concentrations of these elements in the molding sand the larger thickness of the degenerated graphite layer. It should be noticed that the flake graphite layer fundamentally changes ductile iron properties (first of all, smaller strength and a lack of plasticity) in the near-surface layer which can disqualify the given casting. Sulfur diffusion from a molding sand into metal causes also the pearlite layer formation. Increasing the pearlite layer thickness on the boundary casting-mold with increasing 

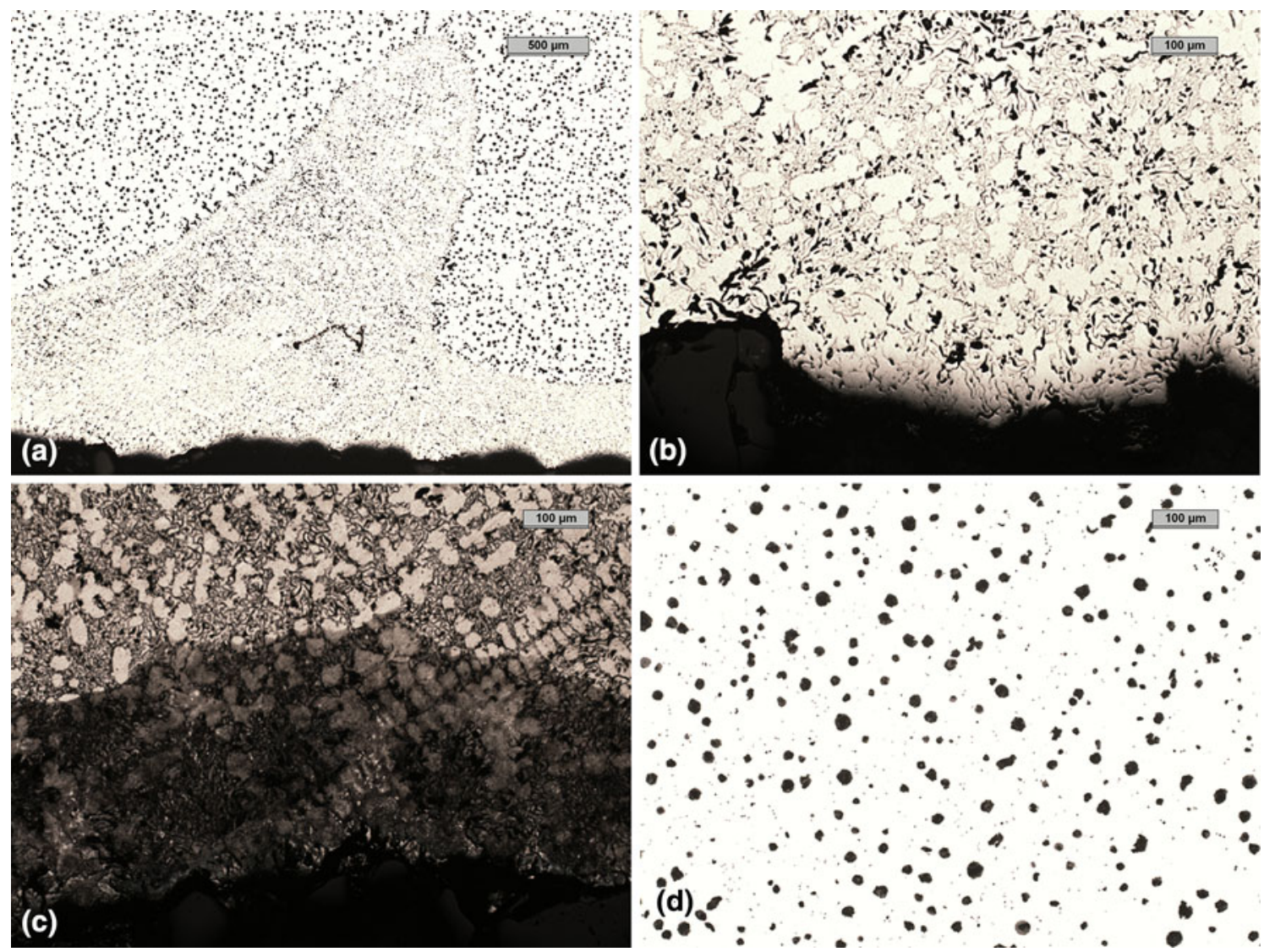

Fig. 10 Photographs of the microstructure of the casting made in the mold of molding sand 4: (a) magnification $25 \times$ - view from the molding sand side, (b) magnification $100 \times$ - view from the molding sand side, (c) magnification $100 \times$ (polished section etched with nital), (d) magnification $100 \times$, middle of the casting

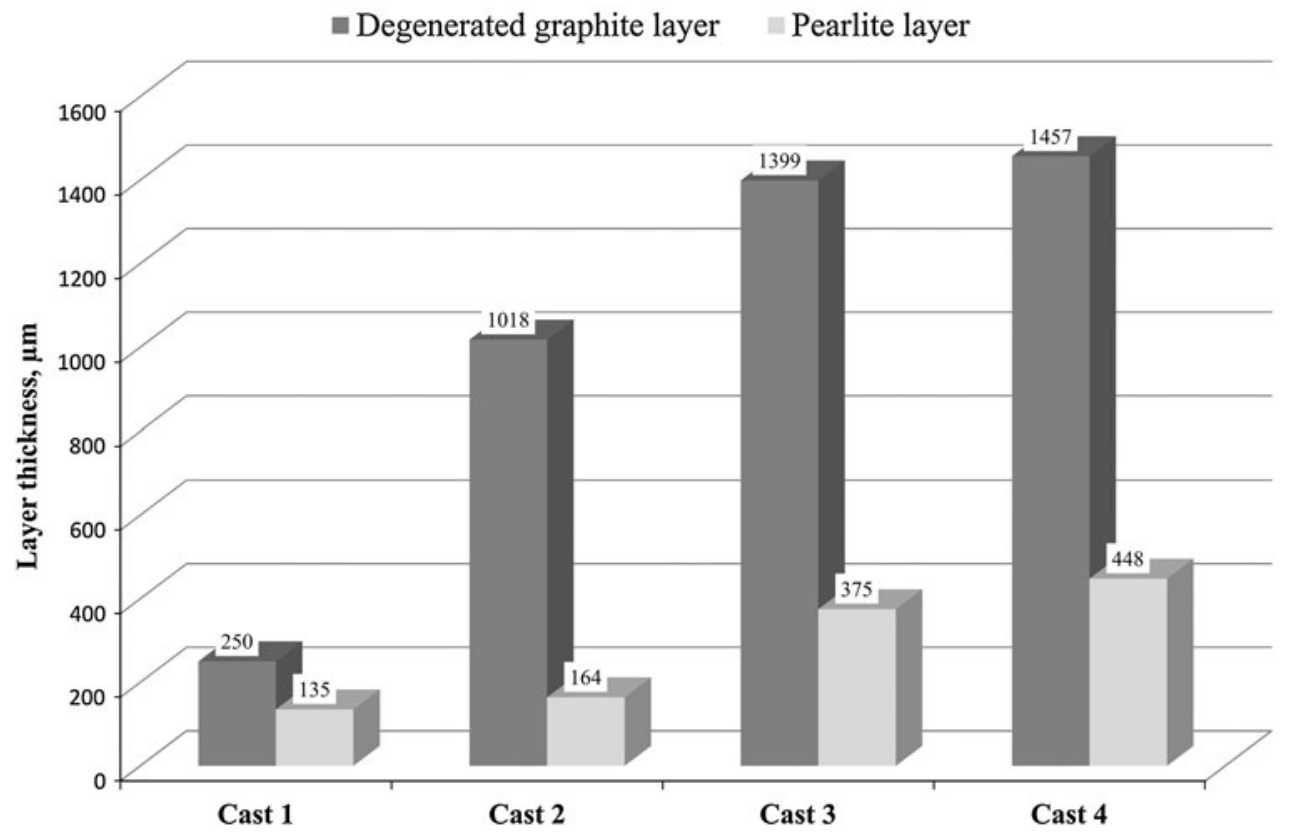

Fig. 11 Influence of the molding sand kind of which the mold was produced on the maximum thickness of the degenerated nodular graphite and pearlite layers 
sulfur content in the molding sand is the result of the pearliteforming sulfur character.

\section{Conclusions}

1. The ignition loss of the molding sand after three cycles of the reclamation treatment is nearly three times larger than that of the molding sand prepared on the fresh highsilica sand. Also matrix indicates significant increases of ignition losses when the number of cycles increases, which indicates the accumulation of a spent binder-on matrix grains - not removed during the reclamation treatment preceding the molding sand preparation.

2. Multiple reclamation treatment causes accumulation of sulfur and nitrogen content in molding sands. Sulfur and nitrogen content in molding sands increase analyzed as a function of their ignition losses indicates nearly linear character.

3. The most intensive gas evolution occurs directly after the mold pouring with liquid metal. Under the investigated conditions, the highest emission of gases occurs in the first $90 \mathrm{~s}$ after pouring with metal. An application of a molding sand of higher ignition losses causes increasing of gas emissions.

4. Castings performed in the mold of the fresh molding sand indicate the best surface quality. When the number of the reclamation cycles was increased the worsening of casting surfaces occured.

5. Along with an increase of ignition losses of molding sands, of which the mold was produced, the thickness of the flake graphite layer increases. Producing mold with using reclaims of higher ignition losses (it means of larger amounts of left over spent binders on matrix grains) causes that the thickness of the flake graphite layer increases.

\section{Acknowledgment}

This work was supported by Polish NCN Project UMO-2011/ 03/B/ST8/05869.

\section{Open Access}

This article is distributed under the terms of the Creative Commons Attribution License which permits any use, distribution, and reproduction in any medium, provided the original author(s) and the source are credited.

\section{References}

1. D.M. Stefanescu, S. Wills, and J. Massone, Quantification of Casting Skin in Ductile and Compacted Graphite Irons and Its Effect on Tensile Properties, Int. J. Metalcast., 2008, 117, p 7-28

2. D.M. Stefanescu and F.R. Juretzko, Study of the Effect of Some Process Variables on the Surface Roughness and the Tensile Properties of Thin Wall Ductile Iron Castings, AFS Trans., 2007, 115, p 1-4

3. J.W. Torrance and D.M. Stefanescu, Investigation on the Effect of Surface Roughness on the Static Mechanical Properties of Thin-Wall Ductile Iron Castings, AFS Trans., 2004, 112, p 757-772

4. I. Riposan, M. Chisamera, S. Stan, and T. Skaland, Factors Influencing the Surface Graphite Degeneration in Ductile Iron Castings in Resin Mold Technology, Proceedings of the Eighth International Symposium on Science and Processing of Cast Iron, Peking, China, 2006

5. S. Boonmee and D. Stefanescu, Effect of Casting Skin on Fatigue Properties of CG Iron, Int. J. Metalcast., 2013, 7, p 15-26

6. M. Górny, Structure Formation of Ultra-Thin Wall Ductile Iron Castings, Akapit Ed, Kraków, 2010

7. M. Holtzer, J. Zych, and K. Retel, Effect of the Interaction of Mould and the Liquid Cast Iron Quality on the Casting Surface, Found. Rev., 1996, 49, p 129-134 (in Polish)

8. B. Grabowska, M. Holtzer, R. Dańko, M. Górny, A. Bobrowski, and E. Olejnik, New BioCo Binders Containing Biopolymers for Foundry Industry, Metalurgija, 2013, 52, p 47-50

9. I. Riposan, M. Chisamera, and S. Stan, Critical Cooling Rate on Carbide Precipitation During Quenching of Austenitic Manganese Steel, China Found., 2010, 7(2), p 163-170

10. N. Ivan, M. Chisamera, and I. Riposan, Graphite Degeneration in Surface Layer of Ductile Iron Castings, Int. J. Cast Met. Res., 2013, 26, p $138-142$

11. R. Dańko, Innovative Developments in Sand Reclamation Technologies, Metallurgy, 2011, 50, p 93-96

12. M. Holtzer, B. Grabowska, S. Żymankowska-Kumon, D. Kwaśniewska-Królikowska, R. Dańko, W. Solarski, and A. Bobrowski, Harmfulness of Moulding Sands with Bentonite and Lustrous Carbon Carriers, Metalurgija, 2012, 51(4), p 437-440. (http://public.carnet. $\mathrm{hr} / \mathrm{metalurg} /$ Metalurgija/2012_vol_51/No_4/MET_51_4_437-440_ Holtzer.pdf) 